\title{
Autonomous Surface Vehicle sebagai Alat Pemantau Lingkungan Menggunakan Metode Navigasi Waypoint
}

\author{
Fadlila Rizki Saputra, Muhammad Rivai \\ Departemen Teknik Elektro, Fakultas Teknologi Elektro, Institut Teknologi Sepuluh Nopember (ITS) \\ E-mail: fadlilarizki.e53@gmail.com, muhammad_rivai@ee.its.ac.id
}

\begin{abstract}
Abstrak-Polusi lingkungan seperti gas dan cairan limbah banyak terdapat pada sungai, danau, serta pantai di sekitar area industri. Polusi tersebut dapat membahayakan kesehatan, sehingga diperlukan sebuah alat untuk pemantau kondisi udara dan air di sekitar perairan tersebut. Autonomous Surface Vehicle (ASV) merupakan robot kapal yang dapat bergerak secara otomatis dari suatu titik ke titik lain dengan menggunakan metode waypoint. ASV dilengkapi dengan Global Positioning System (GPS), sensor gas MQ-7 untuk karbon monoksida (CO), dan keasaman (pH). ASV tersebut mampu menyusuri perairan dengan medan yang sulit dijangkau manusia. Ketika lokasi telah ditentukan, kapal akan bergerak secara otomatis dan mengukur kadar gas CO dalam satuan ppm serta tingkat keasaman air dalam satuan pH yang ada di sekitar lokasi kapal secara realtime. Hasil pengukuran data tersebut langsung dikirimkan ke pengguna melalui telemetri radio. Hasil pengujian sistem yang dilakukan di danau menunjukkan bahwa ASV mampu bergerak secara otomatis maupun manual untuk pengambilan data sensor. Pada pengukuran data sensor gas $\mathrm{CO}$ memiliki rerata kesalahan sebesar $5 \%$, sedangkan pada pengukuran data sensor keasaman memiliki rerata kesalahan $13 \%$. Sistem navigasi waypoint GPS memiliki rerata kesalahan jarak sebesar 2 meter. Berdasarkan perancangan dan pengujian sistem, ASV ini mampu memantau lingkungan secara otomatis sehingga dapat menginformasikan tingkat bahaya bagi kesehatan manusia.
\end{abstract}

Kata kunci-ASV, GPS, Sensor kadar keasaman, Sensor gas, Telemetri.

\section{PENDAHULUAN}

$\mathrm{P}$ ENCEMARAN lingkungan dapat dilihat dari kandungan udara dan air pada suatu lingkungan. Udara merupakan suatu unsur yang sangat penting bagi kehidupan makhluk hidup di bumi. Kandungan gas di udara meliputi Oksigen $\left(\mathrm{O}_{2}\right)$, yang memungkinkan makhluk hidup untuk bernafas. Namun terdapat pula kandungan gas pada udara yang tidak boleh dihirup oleh manusia contohnya adalah gas yang tercipta dari sisa hasil pembakaran yaitu gas karbon monoksida (CO). Jika udara yang dihirup tercemar oleh gas CO maka udara tersebut dapat meracuni tubuh.

Menurut Peraturan Pemerintah Republik Indonesia No.41 tahun 1999, Pencemaran udara adalah masuknya atau dimasukkannya zat, energi, dan/atau komponen lain ke dalam udara ambien oleh kegiatan manusia sehingga mutu udara ambien turun sampai ke tingkat tertentu yang menyebabkan udara ambien tidak dapat memenuhi fungsinya. Pencemaran udara dapat berasal dari kendaraan bermotor dan kegiatan industri.

Terdapat pula cairan limbah yang berada di perairan sehingga mencemari lingkungan sekitar. Untuk mengetahui jenis air yang tidak tercemar dapat diketahui mengukur kadar keasaman atau $\mathrm{pH}$ air tersebut, air yang dapat dikonsumsi memiliki nilai $\mathrm{pH}$ antara $6,5-8,5$.

Polusi lingkungan seperti gas $\mathrm{CO}$ dan cairan limbah tersebut banyak terdapat pada sungai, danau, serta pantai disekitar area industri. Dengan berkembangnya industri dan semakin banyaknya berbagai macam kendaraan maka semakin banyak gas-gas berbahaya yang dihasilkan sehingga dapat mengancam kesehatan tubuh.

Timbulnya permasalahan tersebut maka terciptanya sebuah penelitian untuk memonitoring udara dan gas di sekitar perairan dengan menggunakan alat modern yaitu berupa kapal yang dilengkapi dengan sensor gas MQ7, sensor $\mathrm{pH}$ air dan GPS yang dapat berjalan secara otomatis. Dari monitoring ini dapat diketahui lokasi-lokasi berbahaya dan dapat mengurangi resiko yang timbul akibat gas dan udara yang tercemar oleh gas beracun disekitar perairan tersebut.

\section{DASAR TEORI}

\section{A. Pencemaran Lingkungan}

\section{1) Pencemaran Udara}

Udara dan air merupakan unsur alam yang sangat pokok bagi makhluk hidup yang ada di muka bumi terutama manusia. Tanpa udara dan air yang bersih maka manusia kesehatan manusia akan terganggu dan dapat menyebabkan kematian.

Kualitas udara ambien dari suatu daerah ditentukan oleh jumlah sumber pencemaran atau beban pencemaran dari sumber yang ada di daerah tersebut. Zat-zat yang dikeluarkan oleh sumber pencemar ke udara dan dapat mempengaruhi kualitas udara salah satunya adalah gas Karbon Monoksida 
Udara bersih dan udara kotor menurut WHO.

\begin{tabular}{|l|c|c|}
\hline \multicolumn{1}{|c|}{ Parameter } & Udara Bersih & Udara Tercemar \\
\hline Bahan Partikel & $0,01-0,02 \mathrm{mg} / \mathrm{m} 3$ & $0,07-0,7 \mathrm{mg} / \mathrm{m} 3$ \\
\hline $\mathrm{SO}_{2}$ & $0,003-0,02 \mathrm{ppm}$ & $0,02-2 \mathrm{ppm}$ \\
\hline $\mathrm{CO}$ & $<1 \mathrm{ppm}$ & $5-200 \mathrm{ppm}$ \\
\hline $\mathrm{NO}_{2}$ & $0,003-0,02 \mathrm{ppm}$ & $0,02-0,1 \mathrm{ppm}$ \\
\hline $\mathrm{CO}_{2}$ & $310-330 \mathrm{ppm}$ & $350-0,1 \mathrm{ppm}$ \\
\hline Hidrokarbon & $<1 \mathrm{ppm}$ & $1-20 \mathrm{ppm}$ \\
\hline
\end{tabular}

Karbon monoksida merupakan hasil dari pembakaran yang tidak sempurna, seperti gas CO yang merupakan hasil dari emisi gas buang kendaraan bermotor. Karbon monoksida memiliki sifat senyawa yang tidak berbau, tidak berasa dan pada suhu udara normal berbentuk gas yang tidak berwarna. Kandungan gas CO pada udara yang tidak boleh dihirup oleh manusia karena dapat menyebabkan keracunan, mual, pusing, dan juga sesak nafas, serta kematian apabila menghirup gas $\mathrm{CO}$ dalam jumlah yang tinggi.

\section{2) Pencemaran Air}

Air merupakan kebutuhan pokok bagi makhluk hidup dibumi ini, terutama bagi manusia, karena digunakan dalam kehidupan sehari hari. Air dapat digunakan sebagai air minum apabila air tersebut bersih dan tidak tercemar. Menurut Peraturan Mentri Kesehatan Republik Indonesia, No.416/PER/MENKES/IX/1990 tentang syarat-syarat dan pengawasan kualitas air, air bersih adalah air yang yang digunakan untuk keperluan sehari hari yang kualitasnya memenuhi syarat dan dapat diminum apabila telah dimasak.

Pada saat ini banyak terdapat cairan limbah yang berada di perairan sehingga mencemari lingkungan sekitar, seperti sungai dan danau. Dengan kondisi tersebut maka air tidak layak dikonsumsi oleh manusia karena dapat membahayakan kesehatan. Untuk mengetahui jenis air yang tidak tercemar dapat diketahui dengan berbagai kriteria, yaitu berdasarkan kadar keasaman atau $\mathrm{pH}$ air tersebut. Pada permenkes RI No.416/MENKES/PER/IX/1990 Tanggal 3 September 1990, poin 16 dijelaskan tentang batas air yang dapat dikonsumsi oleh manusia dan makhluk hidup lainnya, yaitu memiliki batas minimum $\mathrm{pH}$ 6,5 dan batas maksimum $\mathrm{pH} 8.5$.

\section{B. Sensor Gas CO}

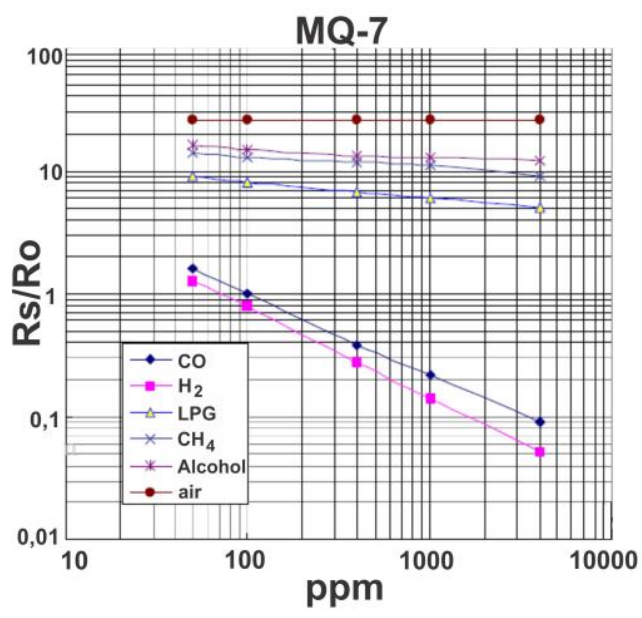

Gambar 1. Grafik Sensitifitas Sensor MQ-7 [1].
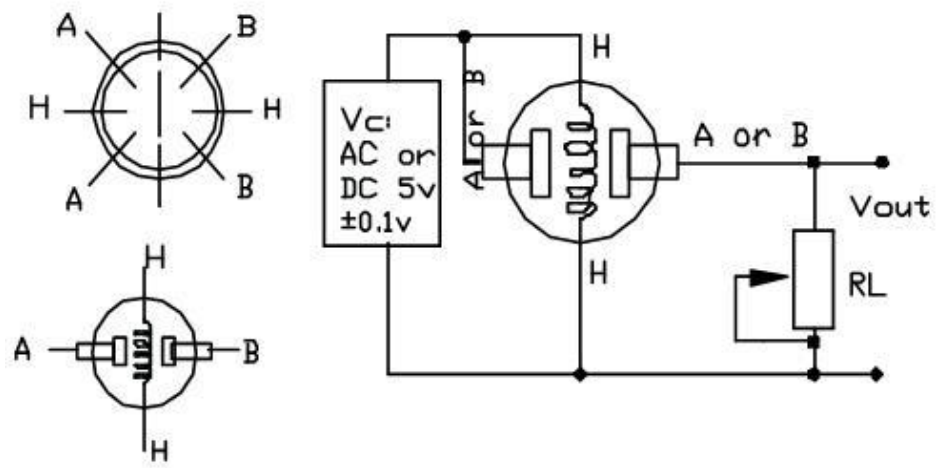

Gambar 2. Rangkaian Sensor MQ7 [1].

Sensor MQ-7 merupakan sensor yang peka terhadap gas karbon monoksida yang merupakan gas hasil dari sisa pembakaran, ditunjukkan pada gambar 1. Sensor ini memiliki sensitivitas tinggi dan waktu respon yang cepat. Pada sensor ini terdapat nilai resistansi sensor (Rs) yang dapat berubah bila terkena gas dan juga sebuah pemanas yang digunakan sebagai pembersihan ruangan sensor dari kontaminasi udara luar. Seperti yang ditunjukkan pada gambar 2, sensor memerlukan dua sumber tegangan, yakni tegangan pemanas $\left(\mathrm{V}_{\mathrm{H}}\right)$ dan tegangan rangkaian sensor (Vc). Tegangan rangkaian digunakan untuk memungkinkan pengukuran tegangan $\left(\mathrm{V}_{\mathrm{RL}}\right)$ antar kedua terminal tahanan beban $\left(\mathrm{R}_{\mathrm{L}}\right)$ yang dihubungkan seri dengan sensor. Suatu sirkit catu daya umum dapat digunakan baik untuk $\mathrm{Vc}$ maupun $\mathrm{V}_{\mathrm{H}}$ untuk memenuhi kebutuhan listrik sensor [2]. Tegangan pemanas dipakai pada pemanas terintegrasi untuk mempertahankan elemen sensor pada suhu tertentu yang optimal [3].

\section{Autonomous Surface Vehicle (ASV)}

Autonomous Surface Vehicle atau ASV merupakan sebuah kapal tanpa awak yang mampu menyusuri perairan secara otomatis. ASV mampu bergerak diatas permukaan air secara otomatis dari suatu lokasi ke lokasi lain dengan bantuan sebuah sistem navigasi berupa waypoint dimana titk-titik lokasinya telah ditentukan sebelumnya.

ASV dilengkapi dengan GPS (Global Positioning System), sensor gas, sensor $\mathrm{pH}$, bluetooth, serta telemetri. Ketika lokasi telah ditentukan, kapal akan bergerak otomatis dan mengukur kadar gas serta kualitas air yang ada di sekitar lokasi kapal secara real-time.

Jenis kapal yang digunakan adalah kapal katamaran (Cattamaran) merupakan jenis kapal yang memiliki dua buah lambung kapal atau dua badan kapal. Dibandingkan dengan kapal lambung tunggal, Katamaran memiliki beberapa kelebihan yang cukup jelas, yaitu adalah stabilitas pada kapal dan memiliki hambatan yang kecil. 

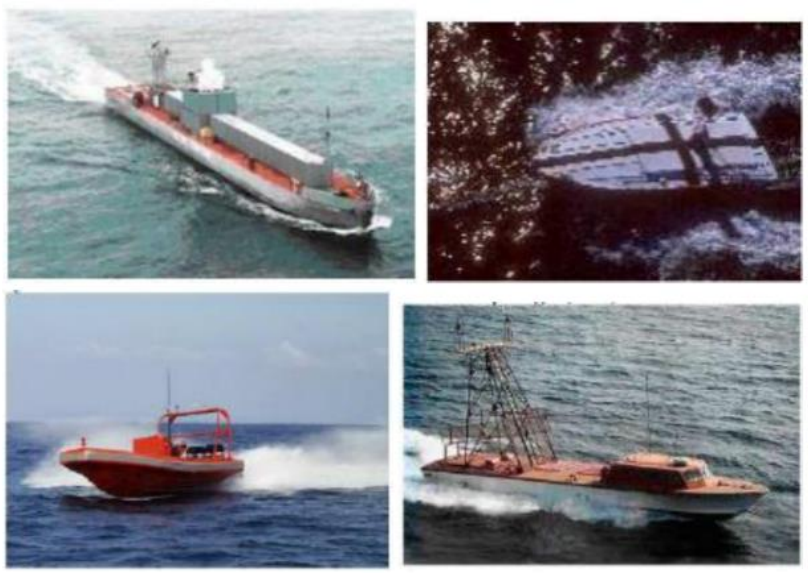

Gambar 3. Contoh kapal tanpa awak [4]

\section{Navigasi Waypoint}

Waypoint merupakan suatu sistem navigasi yang memungkinkan suatu kendaraan dapat bergerak secara otomatis menuju lokasi-lokasi yang telah ditentukan. Prinsip kerja pada navigasi waypoint yaitu dengan cara membuat titiktitik lokasi tujuan yang akan dilalui oleh kapal, kemudian kapal dapat mengikuti jalur yang telah terbentuk menuju titiktitik lokasi yang telah ditentukan tersebut.

Pada sistem navigasi dengan metode waypoint, untuk dapat mengetahui posisi titik-titik tersebut diperlukan data berupa longitude dan lattitute yang dapat dilhat pada google maps. Koordinat lokasi dapat dimasukan ke dalam program mikrokontroller sehingga kapal dapat bergerak berurutan secara otomatis menuju titik tujuan.

\section{E. Pengendali Propotional PID}

PID merupakan sebuah kontroler yang berfungsi sebagai pengendali kapal agar dapat bergerak secara otomatis atau biasa disebut autonomous. Fungsi utama kontrol PID pada Autonomous Surface Vehicle yaitu untuk mengatur arah atau heading kapal agar sesuai dengan tujuan. PID merupakan gabungan dari beberapa unsur yaitu $\mathrm{P}$ (Propotional), I (Integral), dan D (Derivatif). Unsur P, I, maupun D dapat memprcepat respon pada sistem untuk menghilangkan offset. Karena masing-masing mempunyai kelebihan, untuk mentukan besar dari nilai $\mathrm{Kp}$, $\mathrm{Ki}$, maupun $\mathrm{Kd}$ dapat menggunakan cara tuning secara manual untuk mendapatkan nilai yang sesuai.

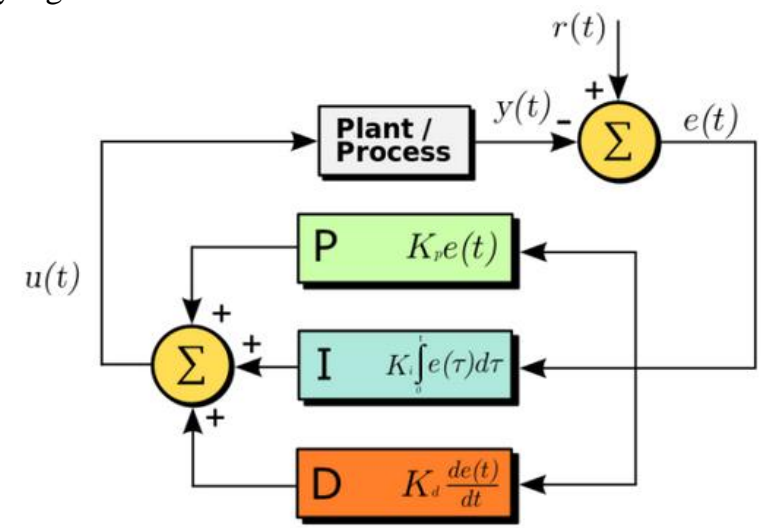

Gambar 4. Kontrol PID [2].

\section{PERANCANGAN SISTEM}

Perancangan perangkat keras meliputi perancangan elektrik dan mekanik, sedangkan perancangan perangkat lunak meliputi pembacaan ADC. Pada gambar 5 menunjukkan blok diagram sistem keseluruhan pada ASV. ASV bergerak berdasarkan perintah yang dikirimkan oleh pengendali berupa HP Android, kemudian pengendali mengirimkan perintah ke mikrokontroler melalui bluetooth HC-05 yang dimiliki oleh ASV. Perintah tersebut berupa pilihan mode yaitu mode otomatis atau mode manual, dan kemudian kapal akan bergerak sesuai perintah tersebut.

Pada saat sistem ASV menjalankan mode manual, maka kapal akan bergerak sesuai perintah dari pengendali. Data yang akan dikirimkan ke komputer berupa data arah gerak kapal, tanpa menampilkan data GPS maupun sensor yang terdapat pada ASV. Ketika sistem menjalankan mode otomatis, maka kapal akan bergerak secara otomatis dengan menggunakan kontrol PID sebagai pengatur gerak otomatis kapal dan memantau kondisi lingkungan disekitar kapal. Kondisi lingkungan yang pantau dan diukur berupa kadar gas $\mathrm{CO}$ dalam satuan PPM serta kualitas air dalam satuan $\mathrm{pH}$, kemudian data tersebut akan dikirimkan secara langsung oleh telemetri ke ground station (personal computer) secara realtime.

\section{A. Perancangan Perangkat Keras}

Komponen elektrik yang akan digunakan pada ASV antara lain Arduino Mega, telemetri, GPS Module, bluetooth, sensor gas MQ7, sensor pH, dan motor DC. Mekanik pada ASV menggunakan kayu balsa yang dilapisi cairan kimia berupa resin.

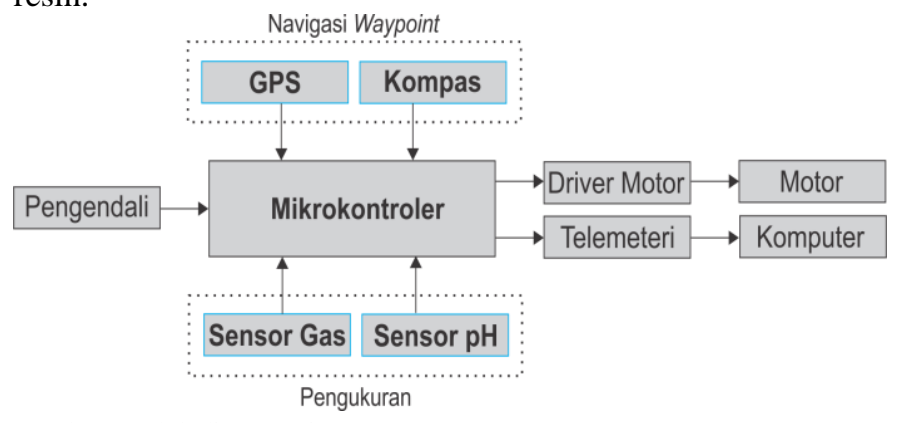

Gambar 5. Blok diagram sistem ASV.

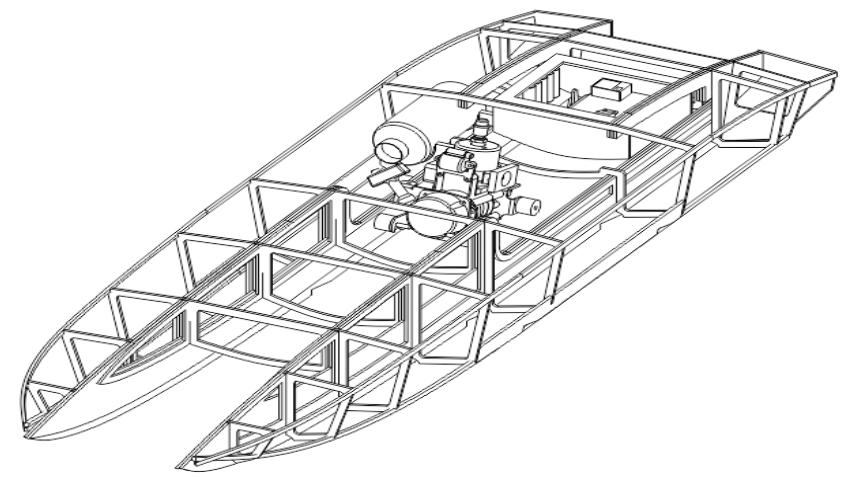

Gambar 6. Desain ASV. 


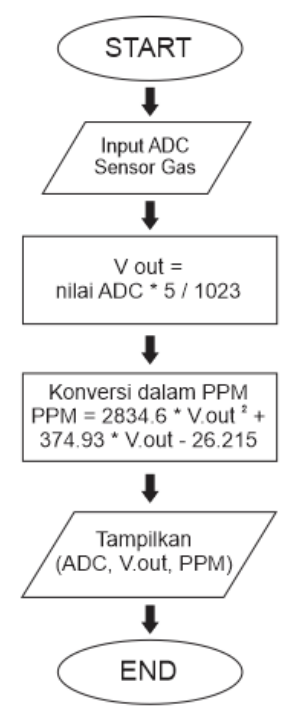

Gambar 7. Flowchart kalibrasi sensor gas.

Autonomous Surface Vehicle menggunakan desain kapal berjenis katamaran (catamaran) seperti gambar 6. Katamaran memiliki dua buah lambung kapal, sehingga jenis kapal katamaran lebih stabil apabila dibandingkan dengan kapal berlambung tunggal.

\section{B. Perangkat Lunak Arduino}

Pada mikrokontroler Arduino Mega, perangkat lunak pada ASV digunakan untuk melakukan berbagai macam proses, yaitu digunakan sebagai pembacaan nilai ADC dari sensor. Pembacaan ADC yang terdapat pada sistem perangkat lunak ini adalah pembacaan ADC dari sensor gas dan sensor $\mathrm{pH}$ untuk kemudian dikalibrasi ke dalam satuan yang telah ditentukan.

\section{Kalibrasi Sensor Gas}

Sensor gas yang digunakan adalah sensor MQ7, memiliki keluaran sinyal analog. Sinyal sensor dikonversi oleh ADC pada Arduino Mega untuk mendapatkan sinyal digital output sensor. Nilai tersebut dikonversi dalam satuan PPM dengan menggunakan model matematis regresi polinomial orde 2 . Proses kalibrasi sensor gas ditunjukan pada gambar 7 .

\section{Kalibrasi Sensor PH}

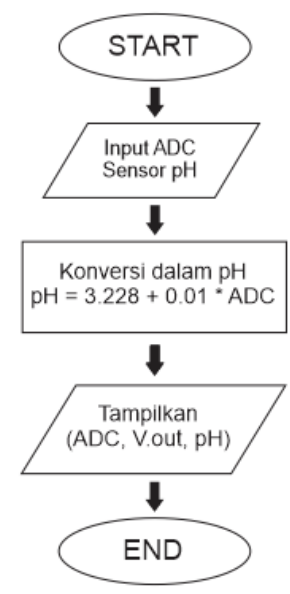

Gambar 8. Flowchart kalibrasi sensor $\mathrm{pH}$.

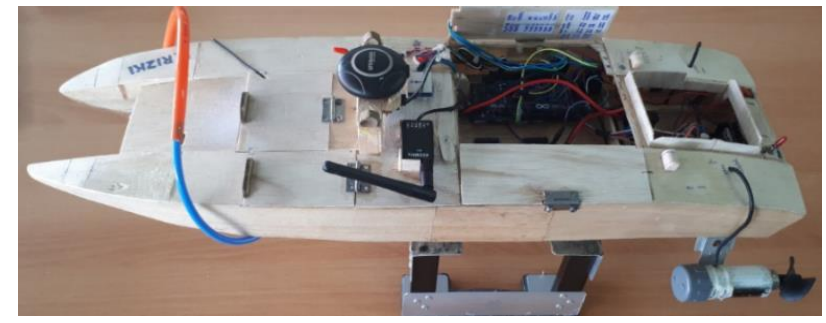

Gambar 9. Autonomous Surface Vehicle.

Sensor pH pada ASV ini juga memiliki keluaran data berupa sinyal analog. Nilai analog tersebut kemudian diproses untuk dikonversi dalam satuan $\mathrm{pH}$ dengan menggunakan model matematis regresi linier. Flowchart dari proses kalibrasi sensor $\mathrm{pH}$ seperti gambar 8 .

\section{PENGUJIAN DAN ANALISIS}

\section{A. Pengujian Mekanik ASV}

Proses pengujian mekanik ASV dilakukan berdasarkan realisasi dari desain yang telah dirancang sebelumnya. Pengujian dilakukan setelah body kapal terbentuk, tahap ini merupakan langkah pertama dalam pembuatan ASV, untuk mengetahui kondisi kapal, apakah layak digunakan atau perlu perbaikan sebelum digunakan. Salah satu indikator kelayakan kapal yaitu tidak adanya kebocoran pada lambung kapal, sehingga kapal dapat mengapung diperairan dengan sempurna.

Tahap selanjutnya, kapal diberikan beban sesuai dengan komponen yang digunakan untuk mengetahui kekuatan kapal pada saat berada diperairan serta melihat performa gerakan kapal dengan beban maksimum yang dibawa. Gambar 9 menunjukkan realisasi dari perancangan penelitian.

\section{B. Pengujian Sensor Gas}

Rangkaian sensor gas MQ-7 merupakan rangkaian sensor dengan tegangan input 5 volt, sedangkan nilai tegangan output dari sensor MQ-7 adalah nilai yang digunakan dalam proses kalibrasi sensor gas CO untuk dikonversi menjadi satuan PPM (Part Per Million). Proses pengujian sensor gas menggunakan wadah tertutup agar gas $\mathrm{CO}$ tidak tercampur dengan gas lainnya dalam proses pengukuran. Gas CO yang dalam pengujian ini berupa asap hasil pembakaran kendaraan bermotor. Proses kalibrasi ini menggunakan alat ukur Carbon Monoxide meter, dengan model 7701 AZ instrument. Pada pengujian tersebut, data yang diambil berupa kadar gas $\mathrm{CO}$ dalam satuan PPM yang terbaca pada $\mathrm{CO}$ meter, dan nilai ADC serta tegangan output yang terbaca pada sensor MQ-7. Alat ukur yang digunakan adalah CO Meter.

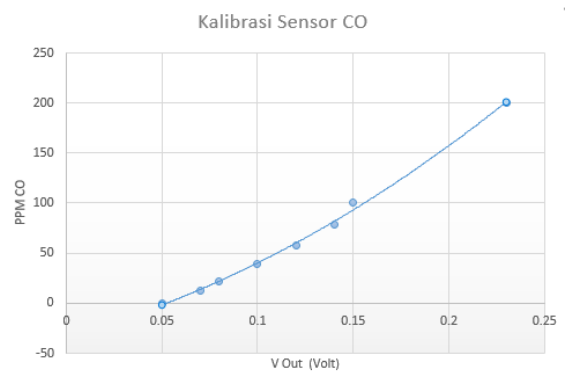

Gambar 10. Kalibrasi sensor gas CO MQ-7. 
Tabel 2.

Perbandingan PPM sensor MQ7 dengan CO meter.

\begin{tabular}{|c|c|c|c|c|}
\hline No. & $\begin{array}{l}\text { CO Meter } \\
\text { (PPM) }\end{array}$ & $\begin{array}{c}\text { Sensor MQ-7 } \\
\text { (PPM) }\end{array}$ & $\begin{array}{l}\text { Selisih } \\
\text { (PPM) }\end{array}$ & $\begin{array}{c}\text { Error } \\
(\%)\end{array}$ \\
\hline 1 & 0 & -0.382 & 0.38 & - \\
\hline 2 & 12 & 13.91964 & 1.9 & 15.9 \\
\hline 3 & 22 & 21.92084 & 0.07 & 0.36 \\
\hline 4 & 39 & 39.624 & 0.6 & 1.6 \\
\hline 5 & 58 & 59.59484 & 1.6 & 2.7 \\
\hline 6 & 78 & 81.83336 & 3.8 & 4.9 \\
\hline 7 & 100 & 93.803 & 6.2 & 6.2 \\
\hline 8 & 200 & 209.96924 & 9.9 & 4.9 \\
\hline \multicolumn{3}{|c|}{ Rata-rata } & 3.075 & 5.257 \\
\hline
\end{tabular}

Tegangan output sensor MQ-7 dan kadar gas (PPM) dimasukkan ke dalam bentuk grafik seperti pada gambar 10 . agar mempermudah dalam mencari model matematisnya. Pencarian model matematis persamaan garis atau kurva menggunakan metode regresi polinomial orde 2. Berdasarkan grafik fungsi regresi polinomial didapatkan fungsi

$$
\text { Regresi : } \mathrm{Y}=2204.5 \mathrm{x}^{2}+509.43 \mathrm{x}-32.928
$$

Data yang dicari adalah kadar gas PPM (sumbu Y) sedangkan data tegangan keluaran sensor (sumbu $\mathrm{X}$ ) merupakan nilai yang diketahui. Dengan memasukkan fungsi ke dalam perhitungan, maka akan didapatkan hasil berupa nilai PPM pada sensor MQ-7 seperti pada tabel 2. Tabel tersebut menunjukkan bahwa terdapat error rata-rata pembacaan $5.257 \%$ dibandingkan dengan hasil pembacaan PPM pada CO-meter. Hal tersebut dapat terjadi karena adanya perubahan nilai tegangan input pada sensor gas MQ-7 dan nilai sensitivitas sensor gas MQ-7 yang lebih rendah dari COmeter.

\section{Pengujian Sensor PH}

Sensor $\mathrm{pH}$ yang digunakan pada penelitian ini merupakan modul sensor $\mathrm{pH}$ yang memilik keluaran berupa ADC dengan input tegangan pada sensor sebesar 5 volt. Nilai ADC output dari modul sensor $\mathrm{pH}$ merupakan nilai yang digunakan dalam proses kalibrasi untuk dikonversi menjadi satuan $\mathrm{pH}$. Pengujian kalibrasi modul sensor $\mathrm{pH}$ dilakukan menggunakan 3 jenis carian yang memiliki $\mathrm{pH}$ berbeda serta menggunakan alat ukur $\mathrm{pH}$ meter Pen Type PH Meter PH-009(I)A. Berikut merupakan hasil pengujian atau pengukuran pada sensor $\mathrm{pH}$ dan $\mathrm{pH}$ meter ditunjukkan pada gambar 11.

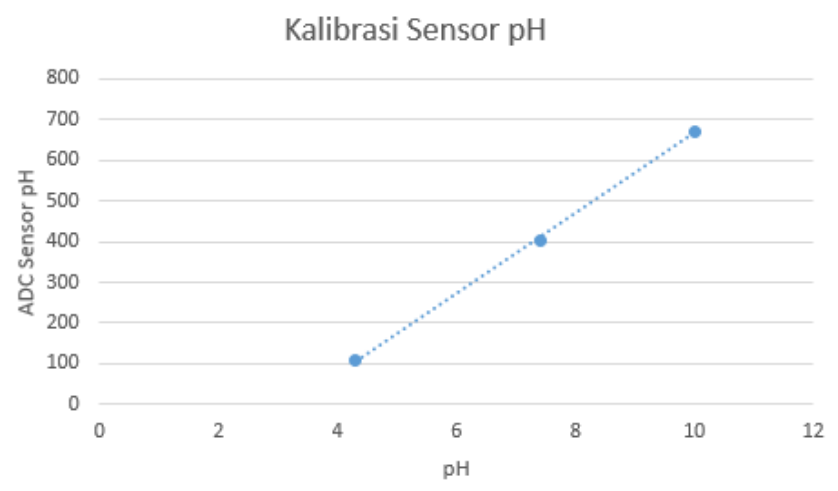

Gambar 11. Kalibrasi sensor pH.
Tabel 3.

Perbandingan $\mathrm{pH}$ antara sensor dengan $\mathrm{pH}$ meter.

\begin{tabular}{ccccc}
\hline \hline No. & $\begin{array}{c}\text { Sensor } \mathrm{pH} \\
(\mathrm{pH})\end{array}$ & $\begin{array}{c}\mathrm{pH} \mathrm{Meter} \\
(\mathrm{pH})\end{array}$ & $\begin{array}{c}\text { Selisih } \\
(\mathrm{pH})\end{array}$ & $\begin{array}{c}\text { Error } \\
(\%)\end{array}$ \\
\hline 1 & 4.322315708 & 4.3 & 0.044 & 1.02 \\
2 & 7.307757675 & 7.4 & 0.092 & 1.26 \\
3 & 10.04792662 & 10 & 0.048 & 0.47 \\
& Rata-rata & & 0.061 & 0.92 \\
\hline \hline
\end{tabular}

Berdasarkan gambar 11, model matematis yang digunakan dalam kalibrasi sensor $\mathrm{pH}$ adalah regresi linier. Regresi linier digunakan untuk mencari fungsi linier yang menyerupai kumpulan titik data $(\mathrm{x}, \mathrm{y})$ yang diketahui. Regresi linier hanya digunakan untuk kurva yang berbentuk mendekati garis lurus. Berikut merupakan persamaan yang digunakan untuk regresi linier :

$$
\mathrm{Y}=\mathrm{a}+\mathrm{b} \mathrm{X}
$$

Dimana, $\mathrm{Y}$ adalah nilai $\mathrm{pH}$ untuk modul sensor $\mathrm{PH}$, ' $\mathrm{a}$ ' adalah konstanta, $\mathrm{b}$ adalah gradien, dan $\mathrm{X}$ adalah nilai $\mathrm{ADC}$ yang terbaca oleh modul sensor $\mathrm{pH}$. Berdasarkan data pada gambar 11, model matematis yang didapatkan ditunjukan pada persamaan (3)

$$
Y=3.228+0.01 \times X
$$

Dengan memasukkan perhitungan nilai $\mathrm{ADC}$ sensor ke dalam persamaan $Y=3.228+0.01 \times X$, menunjukkan bahwa terdapat error rata-rata pembacaan $0.92 \% \quad(0,42$ $1,26 \%$ ) dibandingkan dengan hasil pembacaan $\mathrm{pH}$ pada alat ukur $\mathrm{pH}$ meter, seperti pada table 3.

\section{Pengujian Navigasi Waypoint GPS}

Autonomous Surface Vehicle dapat bergerak secara otomatis dengan menggunakan sistem navigasi waypoint pada GPS. Navigasi waypoint tersebut bekerja berdasarkan titik-titik lokasi yang dipilih, sehingga ASV akan dapat bergerak menuju titik ke titik yang telah ditentukan secara otomatis.

Pengujian sistem navigasi waypoint dilakukan di perairan yang tidak memiliki arus maupun ombak besar dan lokasi yang dipilih dalam pengujian ini adalah Danau 8 ITS seperti gambar 12. Setelah menentukan titik-titik maka kapal akan bergerak ke posisi tujuan secara berurutan sesuai tabel 4 .

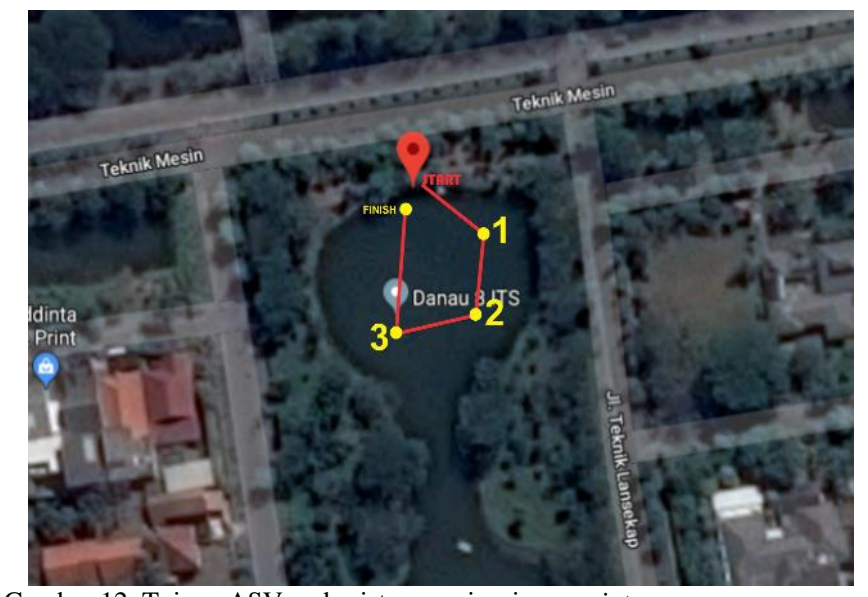

Gambar 12. Tujuan ASV pada sistem navigasi waypoint 
Tabel 4.

Nilai longitude dan lattitude pada sistem waypoint

\begin{tabular}{cccc}
\hline \hline No & Lokasi Tujuan & Lattitude & Longitude \\
\hline 1 & Start (Home) & $-7,286172$ & 112,795979 \\
2 & Waypoint 1 & $-7,286269$ & 112,796094 \\
3 & Waypoimt 2 & $-7,286412$ & 112,796100 \\
4 & Waypoint 3 & $-7,286418$ & 112,795963 \\
5 & Waypoint 4 (Home) & $-7,286172$ & 112,795979 \\
\hline \hline
\end{tabular}

Tabel 5.

Hasil pengujian posisi ASV

\begin{tabular}{ccccc}
\hline \hline Target & Lattitude & Longitude & $\begin{array}{c}\text { Beda } \\
\text { Sudut }\left({ }^{\circ}\right)\end{array}$ & $\begin{array}{c}\text { PID } \\
\text { Sudut }\left({ }^{\circ}\right)\end{array}$ \\
\hline 1 & -7.286271 & 112.796142 & -15.42 & -8.71 \\
2 & -7.286371 & 112.796142 & -6.16 & -2.15 \\
3 & -7.286350 & 112.796051 & 5.48 & 2.28 \\
4 & -7.286324 & 112.796005 & 2.33 & 1.19 \\
5 & -7.286331 & 112.796005 & -0.23 & -1.24 \\
6 & -7.286270 & 112.795921 & 92.94 & 54.75 \\
7 & -7.286208 & 112.795928 & 9.38 & 5.00 \\
\hline \hline
\end{tabular}

Tabel 6.

Hasil pengujian sensor pada ASV.

\begin{tabular}{cccc}
\hline \hline Target & Gas CO (PPM) & $\mathrm{pH}(\mathrm{ADC})$ & $\mathrm{pH}$ \\
\hline 1 & 0 & 348 & 5.5 \\
2 & 2 & 365 & 6.05 \\
3 & 1 & 349 & 5.3 \\
4 & 0 & 357 & 5.68 \\
5 & 2 & 359 & 5.77 \\
6 & 0 & 349 & 5.3 \\
7 & 0 & 365 & 6.05 \\
\hline \hline
\end{tabular}

E. Pengujian Keseluruhan Sistem

Dari pengujian ini, telemetri mampu mengirimkan data dari ASV ke komputer dengan baik. Data yang dikirimkan berupa koordinat lokasi ASV longitude dan lattitude, sensor gas CO, sensor $\mathrm{pH}$. Pada pengujian ini ASV memonitoring kualitas kondisi air dalam satuan $\mathrm{pH}$ dan kondisi gas $\mathrm{CO}$ dalam satuan PPM pada lokasi titik-titik yang ditentukan. Data yang diterima laptop tersebut seperti pada tabel 5 dan 6
Untuk mengetahui error dari pengukuran yang dibaca oleh sensor $\mathrm{pH}$ tersebut dilakukan pengukuran ulang $\mathrm{pH}$ air dengan alat ukur $\mathrm{pH}$ meter dengan mengambil sampel air danau. Pada pengukuran dengan $\mathrm{pH}$ meter menunjukan air danau memiliki pH 6,4, sehingga error rata-rata dari sensor pH adalah $13 \%$ (selisih $\mathrm{pH}$ sebesar 0,35-1,19).

\section{KESIMPULAN}

Autonomous Surface Vehicle (ASV) merupakan kapal tanpa awak yang mampu menyusuri perairan secara otomatis dengan bantuan sistem navigasi waypoint. ASV tersebut mampu bergerak secara otomatis maupun manual berdasarkan pilihan mode pada bluetooth controller. Dari realisasi dan pengujian alat yang dilakukan di danau 8 ITS dapat disimpulkan bahwa sistem navigasi waypoint memiliki rerata kesalahan posisi sebesar 2 meter yang merupakan resolusi dari modul GPS receiver Ublox M8N. Pada kalibrasi sensor gas CO MQ-7, sensor ini memiliki perbedaan dengan $\mathrm{CO}$ meter sebesar 0,4 9,9 ppm dan memiliki rerata kesalahan sebesar 5\%. Kalibrasi tersebut dilakukan dengan menggunakan regresi polinomial orde 2. Pada kalibrasi sensor $\mathrm{pH}$ menggunakan regresi linier memiliki perbedaan pengukuran dengan $\mathrm{pH}$ meter sebesar $0,05-0,09 \mathrm{pH}$ dan rerata kesalahan $0.1 \%$. Sedangkan pada keseluruhan sistem, sensor $\mathrm{pH}$ memiliki perbedaan pengukuran dengan $\mathrm{pH}$ meter sebesar 0,35 - 1,19 $\mathrm{pH}$ dan memiliki rerata kesalahan 13\%. Kesalahan tersebut dikarenakan respon pembacaan sensor $\mathrm{pH}$ dan $\mathrm{CO}$ pada sistem memiliki waktu tunda.

\section{DAFTAR PUSTAKA}

[1] Sparkfun, "Technical Data MQ-7 Gas Sensor" <URL: https://www.sparkfun.com/datasheets/Sensors/Biometric/MQ7.pdf>," 2012.

[2] R. D. Irfan Fachrudin, Muhammad Rivai, "Pemetaan Distribusi Gas Polutan berbasis Autonomous Waypoint Navigation," J. Tek. ITS, vol. 5, no. 2, 2016.

[3] T. Dwita Mido Gumelar, Muhammad Rivai, "Rancang Bangun Wireless Electronic Nose berbasis Teknologi Internet of Things," Inst. Teknol. Sepuluh Nop., 2017.

[4] B. Siswandi, "Perencanaan Unmanned Surface Vehicle (USV) ukuran 3 Meter Tipe Serbu Cepat," Inst. Teknol. Sepuluh Nop., 2012 . 